Note

\section{Effects of Dietary Level of Iron and Ascorbic Acid on Cadmium Toxicity in Rats}

\author{
Tadashi Suzuki and Akira YoshiDA \\ Department of Agricultural Chemistry, \\ Nagoya University, Chikusa, \\ Nagoya, Japan \\ Received January 8, 1979
}

In our laboratory, the preventive and curative effects of dietary iron (400 ppm) and ascorbic acid $(1 \%)$ on the growth depression, anemia and perturbation of several metals in the body of rats fed the diet containing $50 \mathrm{ppm}$ cadmium were investigated. ${ }^{1 \sim 3)}$ However, it is almost unknown whether these levels of supplemented iron and ascorbic acid used in the experiments are the optimum or not., 4 ;

Hill et al., ${ }^{4)}$ reported with chicks that increased dietary iron $(500 \mathrm{ppm})$ corrected the anemia moderately but scarecely improved the growth depressed by an iron deficient diet containing 100 or $200 \mathrm{ppm}$ of cadmium. Whereas, in Japanese quail, effects of dietary iron (30 and $100 \mathrm{ppm}$ ) on the growth depression and anemia produced by $75 \mathrm{ppm}$ of cadmium were investigated by Fox et al ${ }^{53} ; 30 \mathrm{ppm}$ of iron moderately prevented the adverse effects, and $100 \mathrm{ppm}$ of iron prevented the growth depression moderately and the anemia markedly. Therefore, experiment 1 was designed to clarify the amounts of the minimum optimum for supplemental iron and ascorbic acid for complete protection of the adverse effects in rats ingested $50 \mathrm{ppm}$ cadmium. Further, effects of ingested cadmium level on the optimum requirement of iron and ascorbic acid were also investigated in experiment 2.

Male growing rats of the Wistar strain weighing about $100 \mathrm{~g}$ were used in the experiments. The basal diet was a $20 \%$ casein diet containing $0.47 \%$ of calcium, $39 \mathrm{ppm}$ of iron, $16 \mathrm{ppm}$ of copper and $3 \mathrm{ppm}$ of zinc, and the composition was described previously. ${ }^{2)}$ Animals were fed the following diets: In experiment 1; the basal diet, the basal diet supplemented with $50 \mathrm{ppm}$ cadmium as $\mathrm{CdCl}_{2}(50 \mathrm{ppm} \mathrm{Cd}$ diet) and the $50 \mathrm{ppm} \mathrm{Cd}$ diet supplemented with $50 \mathrm{ppm}$ iron as $\mathrm{FeSO}_{4}$ and $0.125 \%$ ascorbic acid, $100 \mathrm{ppm}$ iron and $0.25 \%$ ascorbic acid, $200 \mathrm{ppm}$ iron and $0.5 \%$ ascorbic acid, or $400 \mathrm{ppm}$ iron and $1.0 \%$ ascorbic acid (Fe and AsA supplemented diet). In experiment 2; the basal diet, the 50,100 and $200 \mathrm{ppm} \mathrm{Cd}$ diets, and these diets supplemented with 400,800 and $1600 \mathrm{ppm}$ iron and $1 \%$ ascorbic acid, respectively. Animals were given diets and deionized water ad libitum for 14 or 28 days in experiment 1 or 2 . After the experimental period, the blood collected from tail vein was used to measure the hemoglobin value by the cyanmethemoglobin method. ${ }^{B}$ The liver and kidney rapidly excised, weighed and wet-ashed with a mixture of nitric and perchloric acids $(5: 1, \mathrm{v} / \mathrm{v})$. The metal contents of the tissues were then measured by atomic absorption spectrophotometry.?

In experiment 1 , as shown in Table $\mathrm{I}$, the preventive effects of dietary iron and ascorbic acid on the growth depression and anemia caused by $50 \mathrm{ppm}$ cadmium was almost proportionate to the supplemented levels of these compounds, and dose levels of $400 \mathrm{ppm}$ iron and $1 \%$ ascorbic acid would be needed for the complete prevention of these adverse effects. The concentrations of cadmium in the liver and kidney decreased in proportion to the levels of dietary iron and ascorbic acid, suggesting that the rate of cadmium absorption is depressed as a function of dietary iron and ascorbic acid level. Dietary cadmium caused the reduction of the concentration of iron in the liver, and changes of weights of the liver and kidney, which were not shown in the table, were not observed in rats fed the $50 \mathrm{ppm}$ Cd diet.

In experiment 2, in proportion to the level of ingested cadmium the growth retardation became severe, but the anemia apparently became moderate and this may be due to the severity of the growth depression. Four hundred ppm iron and 1\% ascorbic acid prevented almost completely the growth depression caused by $50 \mathrm{ppm}$ of cadmium as is the case in experiment 1 . However, $800 \mathrm{ppm}$ iron and $1 \%$ ascorbic acid on $100 \mathrm{ppm}$ cadmium, and $1600 \mathrm{ppm}$ iron and $1 \%$ ascorbic acid on $200 \mathrm{ppm}$ cadmium did not prevent the growth depression completely, and at the three levels of cadmium, dietary iron and ascorbic acid caused the similar improvement of the body weight gain of about $2 \mathrm{~g}$ per day, This result suggests that the complete prevention of cadmium toxicity in rats by dietary iron and ascorbic acid is obtained only at the dose levels under $50 \mathrm{ppm}$ cadmium. Whereas, anemia was prevented at all three levels of dietary iron and ascorbic acid. The liver and kidney accumulated cadmium in proportion to the levels of dietary cadmium and the accumulations in the liver and kidney were decreased by dietary iron and ascorbic acid to the extent of one thirds and of a half, respectively, regardless of the iron level. The $\mathrm{Cd}$ diets produced decreases in the iron concentration in the liver and the decreased concentrations are equal irrespective to the dietary cadmium level. 


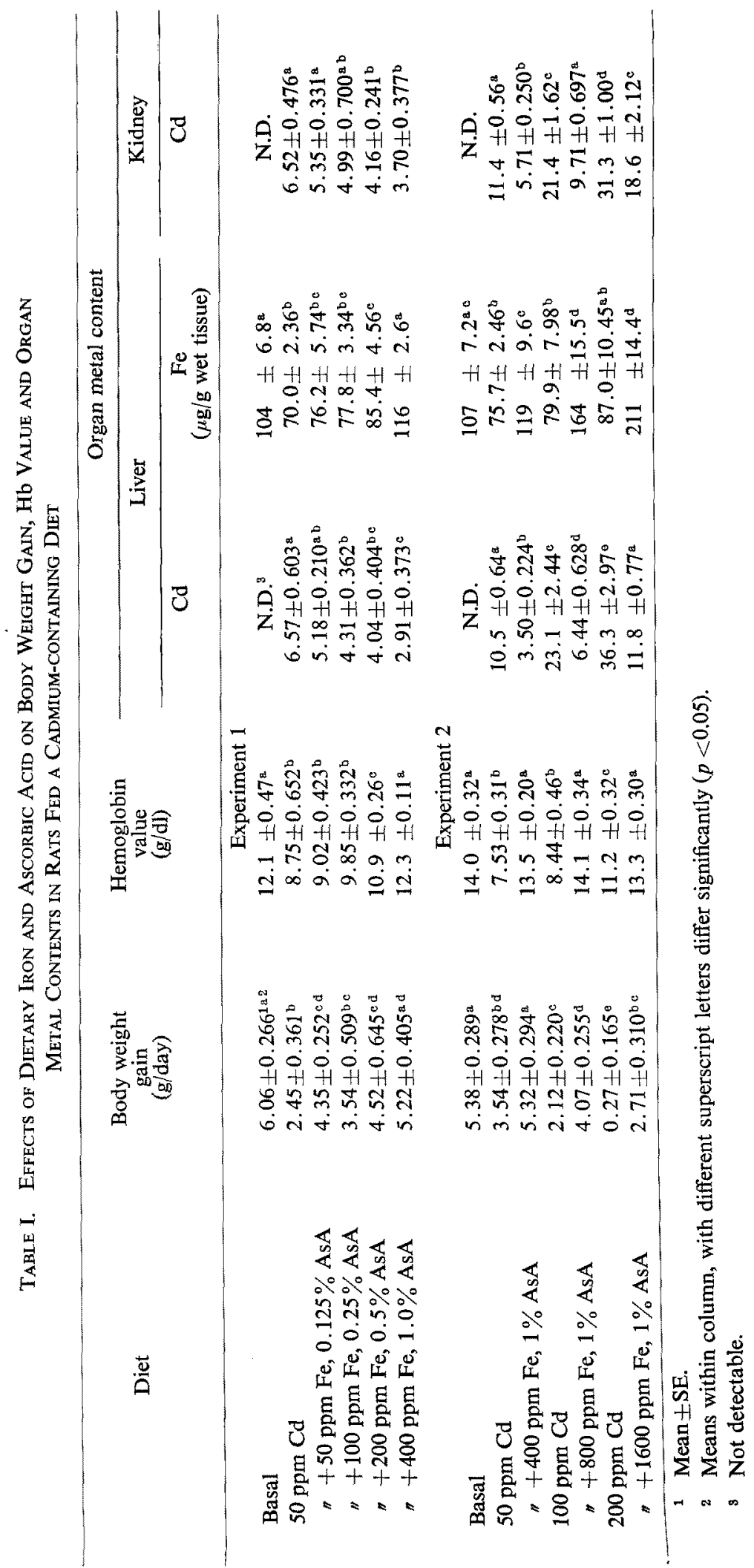




\section{REFERENCES}

1) T. Maji and A. Yoshida, Nutr. Rep. Inter., 10, 139 (1974).

2) T. Suzuki and A. Yoshida, Nutr. Rep. Inter., 16, 769 (1977).

3) T. Suzuki and A. Yoshida, Am. J. Clin. Nutr., 31, 1491 (1978).

4) C. H. Hill, G. Matrone, W. L. Payne and C. W.
Barber, J. Nutr., 80, 227 (1963).

5) M. R. S. Fox, B. E. Fry, Jr, B. F. Harland, M. E. Schertel and C. E. Weeks, J. Nutr., 101, 1295 (1971).

6) D. L. Drabkin and J. H. Austín, J. Biol. Chem., 98, 719 (1932).

7) J. Lener and B. Bibr, J. Agr. Food Chem., 19, 1011 (1971). 